\title{
Highlights
}

- Thermal conductivity of the nanofluid increased with increasing solid concentration

- The maximum increase in thermal conductivity was approximately $65 \%$

- The nanofluid is highly efficient in heat transfer applications

- The pumping power increased as the solid concentration increased

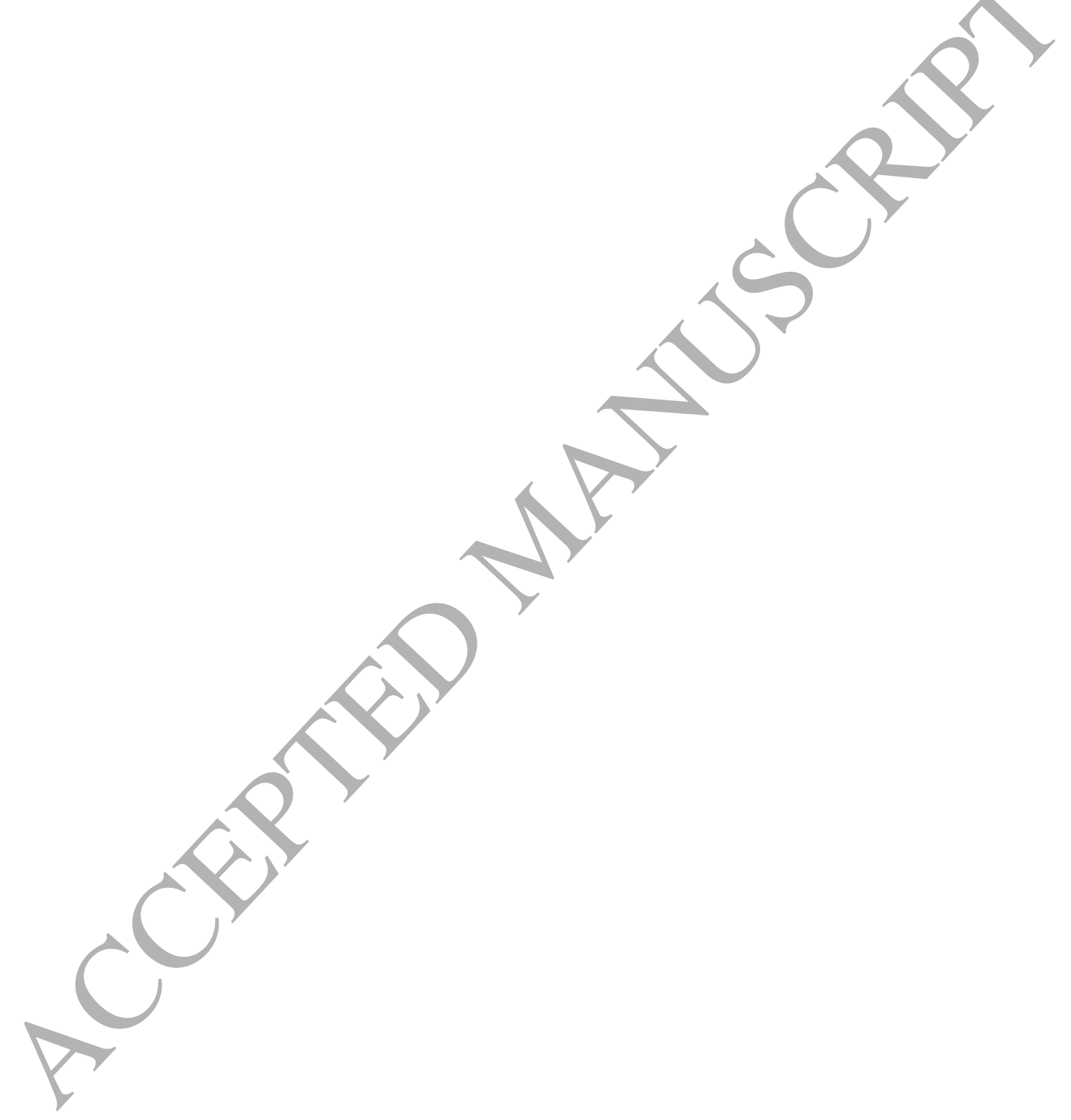




\section{An experimental and theoretical investigation on the effects of adding hybrid nanoparticles on heat transfer efficiency and pumping power of an oil-based nanofluid as a coolant fluid}

\section{Authors' affiliations:}

Meisam Asadi, E-mail: Meisamasadi91@gmail.com

Young Researchers and Elite Club, Semnan Branch, Islamic Azad University, Semnan, Iran.

Amin Asadi (corresponding author), E-mail: Aminasadi64@gmail.com; Ams@et.aau.dk

Department of energy technology, Aalborg University, Pontoppidanstraede 111, DK-9220 Aalborg, Denmark.

Tel: $+45-93562275$

Sadegh Aberoumand (corresponding author), E-mail: $\underline{\text { s.aberoumand@gmail.com }}$

Independent Researcher, Tehran, Iran.

\section{Abstract}

The present work aims to study heat transfer performance and pumping power of $\mathrm{MgO}$ MWCNT/ thermal oil hybrid nanofluid. Using a KD2 Pro thermal analyzer, the thermal conductivity of the samples have been measured. The results showed an increasing trend for the thermal conductivity of the nanofluid by increasing the mass concentration and temperature, in which the maximum enhancement of thermal conductivity was approximately $65 \%$. Predicting the thermal conductivity of the nanofluid, a highly accurate correlation in terms of solid concentration and temperature has been proposed. Moreover, the heat transfer efficiency and pumping power in all the studied range of solid concentrations and temperatures have been theoretically investigated, based on the experimental data of dynamic viscosity and thermal conductivity, for both the internal laminar and turbulent flow regimes. It was observed that the studied nanofluid is highly efficient in heat transfer applications as a coolant fluid in both the laminar and turbulent flow regimes, although it causes a certain penalty in the pumping power.

Keywords: Heat Transfer Efficiency, Pumping Power, Thermal Conductivity, Nano-lubricant, oil-based nanofluid

\section{Introduction}


Thermal oils, undoubtedly, are the dominant cooling media in different industrial heat transfer applications (i.e., heat exchangers, engines thermal management, nuclear cooling, solar collectors, etc.). On the other hand, they have been widely used as a lubricant in the automotive industry. Thermal conductivity and viscosity play important roles in heat transfer performance and pumping power, respectively. Thermal oils are used in high-temperature applications, and it can be economically beneficial if the thermophysical properties of such oils can be enhanced. Choi [1] as the pioneer, introduced nanofluid as a potential way to enhance the fluid's thermophysical properties. After that, many researchers conducted different investigations on thermophysical properties [2-6] and heat transfer [7-10] of various nanofluids.

In recent years, a new class of nanofluids, called hybrid nanofluids has been emerged. Hybrid nanofluids are combinations of two or more different nanoparticles, that result in having enriched working fluid in thermal properties. It has been reported in the literature that hybrid nanofluids possess better heat transfer performance due to their higher thermophysical properties compare to single nanofluids [11].

Enhancing the thermal properties of cooling fluids leads to having compact size cooling systems, increasing the life-cycle of cooling fluids, and improving the efficiency of the cooling systems. Many studies have been conducted on different nanofluids with various combinations of nanoparticles (metallic and non-metallic) and working fluids so far [12-17]. However, there are a limited number of investigations on thermophysical properties of thermal oils. For example, Hemmat Esfe et al. [18] studied the effects of adding nanoparticles on dynamic viscosity of engine oil. They reported $132 \%$ increase in dynamic viscosity. In another experimental study, Asadi and Asadi [19] investigated the viscosity of an engine oil-based hybrid nanofluid containing MWCNT and $\mathrm{ZnO}$ nanoparticles over different temperatures and solid concentrations. Their results indicated that the prepared nanofluid showed Newtonian behavior. Furthermore, they developed a new model to estimate the dynamic viscosity of the nanofluid regarding temperature and solid concentration. As for the thermal conductivity, Aberoumand and Jafarimoghaddam [20] studied the thermal properties of $\mathrm{Cu}$-engine oil nanofluid in a limited range of solid concentration. They found that adding nanoparticles to the base fluid can enhance the thermal conductivity up to $31 \%$ at the concentration of $0.5 \mathrm{wt} \%$. A summary of the recently published literature on thermophysical properties of different thermal oils has been presented in 
table 1. Moreover, a comprehensive review of thermophysical properties of hybrid nanofluids has been recently published by Nabil et al. [21].

Although, in recent years, many investigations have been conducted on thermophysical properties of different combinations of nanoparticles and working fluids, heat transfer performance of the produced nanofluids has not been considered in detail. To put it in another way, changing the thermophysical properties of working fluids (i.e., dynamic viscosity, thermal conductivity, density, specific heat capacity) affects the heat transfer performance of the new fluid. The first step before using the new fluid in real applications is to consider whether the new fluid is a capable heat transfer fluid or not. In this regard, there are a limited number of studies which investigated the capability of the nanofluids as a potential heat transfer fluid based on some figures-of-merit. Cabaleiro et al. [22] investigated the heat transfer capability and pumping power of Graphene nanoplatelets/EG-water nanofluid in various temperatures and solid concentrations for fully developed internal laminar and turbulent flow, based on the experimental results of dynamic viscosity and thermal conductivity. They reported that using this nanofluid would not be advantageous in heat transfer applications. In another investigation, the heat transfer capability of MWCNT- $\mathrm{Al}_{2} \mathrm{O}_{3}$ /thermal oil hybrid nanofluid in both the internal laminar and turbulent flow regimes has been studied by Asadi et al. [23]. They conducted the experiments in various temperatures ranging from $25{ }^{\circ} \mathrm{C}$ to $50{ }^{\circ} \mathrm{C}$ and solid concentrations ranging from $0.125 \%$ to $1.5 \%$. Based on the experimental results of dynamic viscosity and thermal conductivity and using different figures-of-merit, they reported that the produced nanofluid would bring certain advantages as a heat transfer fluid in both the turbulent and laminar flow regimes in all the temperatures and solid concentrations. However, they reported that for internal turbulent flow, the solid concentrations of $1 \%$ and $1.5 \%$ are the only exceptions. There are also some more research which investigated the heat transfer capability of different nanofluids [24-26]

Based on the published reports on thermophysical properties of oil-based nanofluids, it can be concluded that adding nanoparticles leads to enhance the thermal properties of the base fluids. However, the dynamic viscosity of the base fluid shows a considerable increase in some cases. To the best of the authors' knowledge, no comprehensive investigation has been conducted on heat transfer efficiency and pumping power of the oil-based nanofluid regarding the dynamic 
viscosity increase and thermal conductivity enhancement of the nanofluid. In the present study, which is a continuation of the authors' previous work on the rheological behavior of an engine oil-based nano-lubricant containing hybrid nanoparticles of MWCNT/MgO (Asadi et al. ICHMT, 78 (2016) 48-53), the heat transfer efficiency of the MgO-MWCNT/engine oil hybrid nanofluid has been theoretically evaluated in both the internal laminar and turbulent flow regimes. To do so, the thermal conductivity of the nanofluid has been experimentally studied over a different range of temperatures and solid concentrations. Based on the experimental results, a new highly accurate correlation has been proposed to predict the thermal conductivity of the nanofluid. Moreover, the effects of adding the MgO and MWCNT nanoparticles on heat transfer efficiency and pumping power have been theoretically investigated for both the internal laminar and turbulent flow regimes.

\section{Materials and methods}

Two-step method, which is a widely used technique by researchers, has been employed to prepare the samples of MgO-MWCNT/engine oil hybrid nanofluid in six different solid concentrations of $0.25,0.5,0.75,1,1.5$, and $2 \mathrm{wt} \%$. It must be noted that the ratio of using the $\mathrm{MgO}$ and MWCNT nanoparticles was $80 \%$ and $20 \%$, respectively. To preoare a long time stable nanofluid, a magnetic stirrer was used for $2 \mathrm{~h}$. Then the sample was subjected to an ultrasonic processor $(20 \mathrm{kHz}, 1200 \mathrm{~W})$ for $1 \mathrm{~h}$. Researchers proof that ultrasonic processor has a great impact on preparing a long time stable nanofluid by breaking down the agglomeration of nanoparticles in the base fluids [27-31]. Table 2 presents the characteristics of the $\mathrm{MgO}$ and MWCNT nanoparticles and Fig. 1 displays two TEM images of the respective nanoparticles.

\section{Experimental procedures:}

In the previous study [31], the viscosity of the studied sample has been measured using a Brookfield cone and plate viscometer (Brookfield engineering laboratories of the US, $\mathrm{CAP} 2000+$ ) in a different range of solid concentrations (ranging from 0.25 to $2 \mathrm{wt} \%$ ) and temperatures (ranging from $25^{\circ} \mathrm{C}$ to $50{ }^{\circ} \mathrm{C}$ ). The detailed information of the viscometer has been presented in table 3. It must be noted that for assessing the calibration of the viscometer, the viscosity of an engine oil (Castrol GTX Ultraclean 10W40) has been measured, and the results have been compared to those provided by the manufacturer. The results showed that the 
deviation between the measured data by the viscometer and those of the oil's data sheet is less than $2 \%$, which proves the accuracy of the viscometer.

Measuring the thermal conductivity of the nanofluid, a KD2 Pro thermal analyzer (Decagon Devices Inc., USA) was employed. This device, which works based on the transient, hot-wire method, has been widely used by researchers in the literature [29, 32, 33]. In order to stabilize the temperature during the measurements, a water bath temperature was utilized. Fig. 2 shows a schematic view of the thermal conductivity set up.

Using the glycerol, which is supplied by the manufacturer, the calibration of the device has been tested before each set of experiments. Furthermore, the thermal conductivity of water in different temperatures has been measured by the device, and the results have been compared to those available in ASHRAE handbook [34]. Fig. 3 presents the comparison between the measured data and ASHRAE handbook. As can be seen, the maximum deviation between the measured data and the ASHRAE data is less than $1 \%$, which shows the accuracy of the KD2 Pro instrument. Moreover, to scrutinize the repeatability of the measurement, each set of experiments have been repeated three times, and the mean values have been reported. Table 4 presents the detailed information of KD2 Pro device.

\section{Results and discussion}

\subsection{Dynamic viscosity}

In the previously published investigation, Asadi et al. [31] studied the rheological behavior of the $\mathrm{MgO}-\mathrm{MWCNT}$ /engine oil hybrid nanofluid in detail. They reported that the studied nanofluid showed Newtonian behavior over the studied range of shear rates, solid concentrations, and temperatures. Furthermore, their results indicated that the dynamic viscosity of the nanofluid showed increasing trend by increasing the solid concentration. This trend was similar in all the studied temperatures. They reported a maximum increase of $65 \%$ which was at the temperature of $40^{\circ} \mathrm{C}$ and a solid concentration of $2 \%$. On the other hand, they observed that the dynamic viscosity of the nanofluid showed decreasing trend by increasing the temperature. Fig. 4 presents the variations of the dynamic viscosity concerning solid concentrations and temperatures.

\subsection{Thermal conductivity}

\subsubsection{Effect of temperature and solid concentration}


Fig. 5 presents the effects of temperature and solid concentration on the thermal conductivity of MgO-MWCNT/engine oil hybrid nanofluid. As can be seen, the thermal conductivity of the nanofluid showed increasing trend by increasing the temperature and solid concentration. However, the slop of increase by increasing the solid concentration is more noticeable than those of temperatures. The similar trend of thermal conductivity of oil-based nanofluid has been reported before by Aberoumand and Jafarimoghaddam [20] and Aberoumand et al. [35, 36]. Increasing the thermal conductivity of the nanofluid by increasing the solid concentration of nanoparticles can be attributed to the higher conductivity of MWCNT and MgO nanoparticles compared to that of the base fluid. Moreover, increasing the temperature leads to increasing the collisions among the particles which are due to the Brownian motions. This increase in the rate of collisions leads to enhancing the thermal conductivity of the nanofluid.

The percentage of thermal conductivity enhancement (TCE)can be calculated as follow:

T.C.E $=\left(\frac{k_{n f}-k_{b f}}{k_{b f}}\right) \times 100 \%$

It is interesting to note that the maximum enhancement in thermal conductivity of utilized nanofluid is approximately $62 \%$ which took place at the solid concentration of $2 \%$ and temperature of $50{ }^{\circ} \mathrm{C}$. Fig. 6 shows the thermal conductivity enhancement of the studied nanofluid in different solid concentrations and temperatures.

\subsubsection{Proposed correlation}

It is known that several parameters are affecting the thermal conductivity of nanofluids such as temperature, the solid yolume fraction of nanoparticles, size and shape of the particles, and so forth. Several theoretical models have been thus far proposed by different researchers to predict the thermal conductivity of different suspensions of nanofluids. A summary of the widely used theoretical models has been presented in table 5 .

However, it has been proofed by many researchers that these classical models are not able to predict the thermal conductivity of different mixture of nanoparticles in conventional fluids. As a result, many researchers have tried to propose new models to predict the thermal conductivity behavior of different nanofluids based on the experimental data. On the other hand, conducting 
experimental research is costly, time-consuming, and in some cases, the experimental facilities are not available. Thus, in the present study, an attempt has been made to propose a reliable correlation to predict the thermal conductivity of the studied oil-based hybrid nanofluid in the acceptable range of accuracy. The proposed correlation, which is in terms of temperature $\left({ }^{\circ} \mathrm{C}\right)$ and solid concentration (\%), is as follows:

$$
k_{n f}(T, \varphi)=0.162+(0.691) \varphi+(0.00051) T
$$

Fig. 7 shows a comparison between the experimental data and correlation output. As can be seen, the proposed correlation predicts the thermal conductivity of the nanofluid precisely.

Furthermore, to investigate the accuracy and maximum error of the proposed correlation, the deviation analysis has been performed based on the following equation:

Deviation $=\left[\frac{k_{\text {Corr. }}-k_{E x p .}}{k_{E x p .}}\right] \times 100 \%$

where the subscribes Corr. and Exp. represent the correlation prediction and experimental data, respectively. The results of deviation analysis have been presented in Fig. 8. As can be seen, the maximum deviation of the proposed model is well under $3 \%$, which proofs the accuracy of the proposed model.

\subsection{Efficiency of the nanofluid as a coolant fluid in heat transfer applications}

It is known that adding nanoparticles to the conventional working fluids (i.e., water, ethylene glycol, and oil) leads to enhance the thermal properties of the working fluids since these nanoparticles have higher thermal conductivity. However, it also leads to increase the dynamic viscosity of the working fluids. Thus to select a proper fluid for cooling or heating applications, it is, first of all, necessary to scrutinize the heat transfer efficiency of the fluid in different flow regimes; laminar and turbulent.

\subsubsection{Efficiency of nanofluid in internal laminar flows}

Investigating the heat transfer efficiency of the studied nanofluid in internal laminar flow regime, Mouromtseff [37] and Prasher et al. [38] proposed two different figures-of-merit. The general form of the Mouromtseff number is as follows: 


$$
M o=\frac{\rho^{a} k^{b} c_{p}^{d}}{\mu^{e}}
$$

where $\boldsymbol{\rho}, \boldsymbol{k}, \boldsymbol{c}_{p}$, and $\boldsymbol{\mu}$ represent density, thermal conductivity, specific heat capacity, and dynamic viscosity, respectively. Furthermore, the exponents $\boldsymbol{a}, \boldsymbol{b}, \boldsymbol{d}$, and $\boldsymbol{e}$ are the appropriate values to the heat transfer mode of interest and the corresponding heat transfer correlation [39]. As for the case of fully developed internal laminar flow, it is known that the Nusselt number is a constant [40]. Therefore, the thermal conductivity is the only thermal factor which has a certain effect on the heat transfer coefficient. Thus, for the case of fully developed internal laminar flow, the ratio of Mo number of nanofluid to that of the base fluid is equal to the ratio of the nanofluid's thermal conductivity to the thermal conductivity of the base fluid [39].

$\frac{M o_{n f}}{M o_{b f}}=\frac{k_{n f}}{k_{b f}}$

For the ratios of $\mathbf{M o}$ number higher than 1, the nanofluid can be considered as beneficial fluid in heat transfer applications in fully developed internal laminar flows. Fig. 9 shows the figure-ofmerit (Mo number) for the studied nanofluid. As can be clearly seen, the Mo number is higher than 1 in all the studied temperatures and solid concentrations. Thus it can be concluded that using this nanofluid instead of the base fluid (oil) can be beneficial in the case of fully developed internal laminar flow regime.

In another study, Prasher et al. [38] suggested another figure-of-merit for the fully developed internal laminar flow regime as follows:

$\frac{C_{\mu}}{C_{k}}=\frac{\left(\mu_{n f}-\mu_{b f}\right) / \mu_{b f}}{\left(k_{n f}-k_{b f}\right) / k_{b f}}$

They indicated that for the ratios less than $4\left(\boldsymbol{C}_{\boldsymbol{\mu}} / \boldsymbol{C}_{\boldsymbol{k}}<\mathbf{4}\right)$, using the nanofluid instead of the base fluid is always considered as beneficial fluid for heat transfer applications. Fig. 10 presents the figure-of-merit based on the Prasher et al. [38] model. It is crystal clear that the Prasher at al. [38] ratio for the studied nanofluid is by far less than 4 in all the studied temperature and solid concentrations. Thus, based on this two figures-of-merit, it can be concluded that using MgOMWCNT/engine oil hybrid nanofluid instead of the base fluid (oil) can be beneficial in heat transfer application as a coolant fluid in internal laminar flow regime. It is a common knowledge that in most of the practical applications, we encounter with turbulent flow regimes. However, there are some exceptions. For instance, in the applications in which a highly viscose fluid, such 
as thermal oils, flow in narrow passages or small pipes, the laminar flow regime will experience [41]. On the other hand, the primary application of utilizing oils as a heat transfer and lubricant fluid is in energy management and heat transfer applications in automotive industry. In such applications, the engine oils are used as a coolant and lubricant media in very narrow gaps between moving parts of the engines. The flow regime in such narrow gaps can be considered as laminar. Therefore, based on the presented results of heat transfer efficiency of the studied nanofluid, using the MWCNT-MgO/engine oil hybrid nanofluid instead of the based fluid (pure oil) can be recommended in heat transfer and energy management applications, although it possesses higher viscosity.

\subsubsection{Efficiency of nanofluid in internal turbulent flows}

As for the internal turbulent flow, the figure-of-merit, based on the Mouromtseff number [37], is as follows:

Mo $=\frac{\rho^{0.8} k^{0.67} c_{p}^{0.33}}{\mu^{0.47}}$

Again for the ratios of the Mo number higher than 1 , the nanofluid considered as a beneficial fluid in heat transfer applications. Thus the higher the Mo number, the better the nanofluid in heat transfer applications as a coolant fluíd.

In the present investigation, the values of the dynamic viscosity and thermal conductivity have been experimentally calculated. As for the density and specific heat capacity, Takabi and Salehi [42] have proposed two correlations to calculate these two factors for hybrid nanofluids as follows:

$\rho_{n f}=\left(1-\varphi_{p}\right) \rho_{b f}+\varphi_{p, 1} \rho_{1}+\varphi_{p, 2} \rho_{2}$

$c_{P, n f}=\frac{(1-\varphi) \rho_{n f} c_{P, b f}+\varphi_{p, 1} \rho_{1} c_{p, 1}+\varphi_{p, 2} \rho_{2} c_{p, 2}}{\rho_{n f}}$

where $c_{p}, \rho$, and $\varphi$ represent specific heat capacity, density, and solid concentration, respectively.

Fig. 11 shows the figure-of-merit (heat transfer efficiency) of the studied nanofluid in internal turbulent flow regimes based on the Mouromtseff Number. It is revealed that using these nanofluids instead of base fluid (oil) can be beneficial in all the studied solid concentrations and temperatures. 


\subsection{Effect of adding nanoparticles on pumping power}

Fig. 12 presents the effect of adding nanoparticles on pumping power in different temperatures for both the internal laminar and turbulent flow regimes. Considering a circular tube with a uniform heat flux at the wall and the same mass flow rate for both the nanofluid and the base fluid (oil). The increase in pumping power, in this case, can be evaluated for both the internal laminar and turbulent flow regimes as follows [43]:

$$
\begin{aligned}
& \left(\frac{\dot{W}_{n f}}{\dot{W}_{b f}}\right)_{L . f}=\left(\frac{\mu_{n f}}{\mu_{b f}}\right) \cdot\left(\frac{\rho_{b f}}{\rho_{n f}}\right)^{2} \\
& \left(\frac{\dot{W}_{n f}}{\dot{W}_{b f}}\right)_{T . f}=\left(\frac{\mu_{n f}}{\mu_{b f}}\right)^{0.25} \cdot\left(\frac{\rho_{b f}}{\rho_{n f}}\right)^{2}
\end{aligned}
$$

where $\dot{\boldsymbol{W}}$ represents the pumping power and subscribes L.f $_{\text {f }}$ and ${ }_{T . f}$ standing for laminar flow and turbulent flow. From the energy management point of view, the ratio of less than $1\left(\dot{\boldsymbol{W}}_{n f} \dot{\boldsymbol{W}}_{b f}<\boldsymbol{1}\right)$ is desirable to prevent any increase in energy consumption in both the internal laminar and turbulent flow regimes. As can be seen in Fig. 12, the ratios are higher than 1 in all the studied solid concentration and temperature for both the internal laminar and turbulent flow regimes. However, the increase in pumping power for turbulent flow is by far lower than that of laminar flow. Moreover, the maximum pumping power is at the temperature of $40{ }^{\circ} \mathrm{C}$ in all the studied solid concentration for both the flow regimes. It is interesting to note that the maximum increase in pumping power for the laminar flow is approximately $75 \%$ while this increase for the turbulent flow is well under $20 \%$, which happened at the temperature of $40{ }^{\circ} \mathrm{C}$ and the solid concentration of $2 \%$ in both the cases. From what has been discussed above, it can be concluded that although replacing the base fluid (engine oil) with the MgO-MWCNT/engine oil hybrid nanofluid causing a certain penalty in pumping power, the heat transfer efficiency of the fluid will be enhanced as well. In this case, replacing the base fluid with the nanofluid is completely depends on the applications in which the nanofluid will be used.

\section{Conclusion}

In the present study, the heat transfer efficiency and pumping power of the MWCNT$\mathrm{MgO} /$ engine oil hybrid nanofluid have been theoretically investigated. In this regard, the thermal 
conductivity of the nanofluid has been experimentally measured at various temperatures $\left(25^{\circ} \mathrm{C}\right.$ to $\left.50{ }^{\circ} \mathrm{C}\right)$ and solid concentrations $(0.25 \%$ to $2 \%)$. It has been observed that the thermal conductivity of the nanofluid enhances as the solid concentration increased. This increasing trend has been repeated in all the studied temperatures. The maximum enhancement took place at the temperature of $50{ }^{\circ} \mathrm{C}$ and the solid concentration of $2 \%$ by $65 \%$. Based on the experimental measurement, a new highly precise correlation to predict the thermal conductivity of the nanofluid has been presented in the studied range of temperatures and solid concentrations. Furthermore, the heat transfer efficiency of the nanofluid as well as the pumping power in all the studied temperatures and solid concentrations and for both the internal laminar and turbulent flow has been theoretically investigated based on the experimental résults of thermal conductivity and dynamic viscosity. As for the heat transfer efficiency, it is revealed that using this nanofluid instead of the base fluid (engine oil) is highly efficient in both the internal laminar and turbulent flow regimes. The results of the pumping power indicated that using the studied nanofluid will cause a certain penalty in pumping power for the laminar and turbulent flow regimes.

\begin{tabular}{|l|l|}
\hline Nomenclature & Subscripts \\
$K:$ Thermal conductivity & $b f:$ Base fluid \\
$C_{p}:$ Specific heat capacity & $n f:$ Nanofluid \\
$M o:$ Mouromtseff number & $p$ : Particle \\
W: pumping power & \\
Greeks & \\
$\varphi:$ nanoparticles volume fraction & \\
$\rho:$ Density & \\
$\tau:$ Shear stress & \\
$\gamma:$ Shear strain & \\
$\mu:$ Dynamic viscosity & \\
\hline
\end{tabular}

\section{References}


[1] S. U. S. Choi, "Enhancing thermal conductivity of fluids with nanoparticles," ASME-PublicationsFed, vol. 231, pp. 99-106, 1995.

[2] A. Asadi, M. Asadi, M. Siahmargoi, T. Asadi, and M. Gholami Andarati, "The effect of surfactant and sonication time on the stability and thermal conductivity of water-based nanofluid containing $\mathrm{Mg}(\mathrm{OH}) 2$ nanoparticles: An experimental investigation," International Journal of Heat and Mass Transfer, vol. 108, Part A, pp. 191-198, 5// 2017.

[3] A. Asadi and S. Sadodin, "Development of new model to predict dynamic viscosity of ethylene glycol based nanofluid containing $\mathrm{Mg}(\mathrm{OH})$ 2."

[4] M. H. Esfe, S. Saedodin, and A. Asadi, "An empirical investigation on the dynamic viscosity of Mg $(\mathrm{OH})$ 2-ethylene glycol in different solid concentrations and proposing new correlation based on experimental data," International Journal of Natural and Engineering Sciences, vol.8, pp. 29-34, 2014.

[5] M. H. Esfe, S. Saedodin, A. Asadi, and A. Karimipour, "Thermal conductivity and viscosity of Mg $(\mathrm{OH})$ 2-ethylene glycol nanofluids," Journal of Thermal Analysis and Calorimetry, vol. 120, pp. 1145-1149, 2015.

[6] M. H. Esfe, S. Wongwises, A. Naderi, A. Asadi, M. R. Safaei, H. Rostamian, et al., "Thermal conductivity of $\mathrm{Cu} / \mathrm{TiO}$ 2-water/EG hybrid nanofluid: Experimental data and modeling using artificial neural network and correlation," International Communications in Heat and Mass Transfer, vol. 66, pp. 100-104, 2015.

[7] M. H. Esfe, S. Saedodin, O. Mahian, and S. Wongwises, "Heat transfer characteristics and pressure drop of $\mathrm{COOH}$-functionalized DWCNTs/water nanofluid in turbulent flow at low concentrations," International Journal of Heat and Mass Transfer, vol. 73, pp. 186-194, 2014.

[8] M. Hemmat Esfe, S. Saedodin, O. Mahian, and S. Wongwises, "Thermophysical properties, heat transfer and pressure drop of $\mathrm{COOH}$-functionalized multi walled carbon nanotubes/water nanofluids," International Communications in Heat and Mass Transfer, vol. 58, pp. 176-183, 11// 2014.

[9] K. Wongcharee and S. Eiamsa-ard, "Heat transfer enhancement by using CuO/water nanofluid in corrugated tube equipped with twisted tape," International Communications in Heat and Mass Transfer, vol. 39, pp. 251-257, 2// 2012.

[10] H. Hu, H. Peng, and G. Ding, "Nucleate pool boiling heat transfer characteristics of refrigerant/nanolubricant mixture with surfactant," international journal of refrigeration, vol. 36, pp. 1045-1055, 2013.

[11] M. H. Hamzah, N. A. C. Sidik, T. L. Ken, R. Mamat, and G. Najafi, "Factors affecting the performance of hybrid nanofluids: A comprehensive review," International Journal of Heat and Mass Transfer, vol. 115, pp. 630-646, 2017/12/01/ 2017.

[12] M. Bahiraei and S. Heshmatian, "Application of a novel biological nanofluid in a liquid block heat sink for cooling of an electronic processor: Thermal performance and irreversibility considerations," Energy Conversion and Management, vol. 149, pp. 155-167, 2017/10/01/ 2017.

[13] M. A. Khairul, K. Shah, E. Doroodchi, R. Azizian, and B. Moghtaderi, "Effects of surfactant on stability and thermo-physical properties of metal oxide nanofluids," International Journal of Heat and Mass Transfer, vol. 98, pp. 778-787, 7// 2016.

[14] A.Hernández Battez, J.L.Viesca, R.González, D.Blanco, E.Asedegbega A.Osorio., Friction reduction properties of a CuO nanolubricant used as lubricant for a NiCrBSi coating, Wear, 268, 1-2, pp. 325-328, 2010.

[15] M. A. Kedzierski and M. Gong, "Effect of CuO nanolubricant on R134a pool boiling heat transfer," international journal of refrigeration, vol. 32, pp. 791-799, 2009. 
[16] P. Kalita, A. P. Malshe, S. A. Kumar, V. Yoganath, and T. Gurumurthy, "Study of specific energy and friction coefficient in minimum quantity lubrication grinding using oil-based nanolubricants," Journal of Manufacturing Processes, vol. 14, pp. 160-166, 2012.

[17] M. Bahiraei and S. Heshmatian, "Efficacy of a novel liquid block working with a nanofluid containing graphene nanoplatelets decorated with silver nanoparticles compared with conventional CPU coolers," Applied Thermal Engineering, vol. 127, pp. 1233-1245, 2017/12/25/ 2017.

[18] M. H. Esfe, M. Afrand, S. Gharehkhani, H. Rostamian, D. Toghraie, and M. Dahari, "An experimental study on viscosity of alumina-engine oil: Effects of temperature and nanoparticles concentration," International Communications in Heat and Mass Transfer, vol. 76, pp. 202-208, 2016.

[19] M. Asadi and A. Asadi, "Dynamic viscosity of MWCNT/ZnO-engine oil hybrid nanofluid: An experimental investigation and new correlation in different temperatures and solid concentrations," International Communications in Heat and Mass Transfer.

[20] S. Aberoumand and A. Jafarimoghaddam, "Experimental study on synthesis, stability, thermal conductivity and viscosity of Cu-engine oil nanofluid," Journal of the Taiwan Institute of Chemical Engineers, vol. 71, pp. 315-322, 2// 2017.

[21] M. Nabil, W. Azmi, K. Hamid, N. Zawawi, G. Priyandoko, and R. Mamat, "Thermo-physical properties of hybrid nanofluids and hybrid nanolubricants: A comprehensive review on performance," International Communications in Heat and Mass Transfer, vol. 83, pp. 30-39, 2017.

[22] D. Cabaleiro, L. Colla, S. Barison, L. Lugo, L. Fedele, and S. Bobbo, "Heat transfer capability of (ethylene glycol+ water)-based nanofluids containing graphene nanoplatelets: Design and thermophysical profile," Nanoscale research letters, vol. 12, p. 53, 2017.

[23] A. Asadi, M. Asadi, A. Rezaniakolaei, L. A. Rosendahl, M. Afrand, and S. Wongwises, "Heat transfer efficiency of Al2O3-MWCNT/thermal oil hybrid nanofluid as a cooling fluid in thermal and energy management applications: An experimental and theoretical investigation," International Journal of Heat and Mass Transfer, vol. 117, pp. 474-486, 2// 2018.

[24] G. Żyła, "Viscosity and thermal conductivity of MgO-EG nanofluids," Journal of Thermal Analysis and Calorimetry, vol. 129, pp. 171-180, 2017.

[25] A. Asadi, M. Asadi, A. Rezaniakolaei, L. A. Rosendahl, and S. Wongwises, "An experimental and theoretical investigation on heat transfer capability of $\mathrm{Mg}(\mathrm{OH}) 2 / \mathrm{MWCNT}$-engine oil hybrid nano-lubricant adopted as a coolant and lubricant fluid," Applied Thermal Engineering, vol. 129, pp. 577-586,2018/01/25/2018.

[26] G. J. Tertsinidou, C. M. Tsolakidou, M. Pantzali, M. J. Assael, L. Colla, L. Fedele, et al., "New measurements of the apparent thermal conductivity of nanofluids and investigation of their heat transfer/capabilities," Journal of Chemical \& Engineering Data, vol. 62, pp. 491-507, 2016.

[27] M. Afrand, "Experimental study on thermal conductivity of ethylene glycol containing hybrid nano-additives and development of a new correlation," Applied Thermal Engineering.

[28] M. Afrand, E. Abedini, and H. Teimouri, "How the dispersion of magnesium oxide nanoparticles effects on the viscosity of water-ethylene glycol mixture: Experimental evaluation and correlation development," Physica E: Low-dimensional Systems and Nanostructures.

[29] M. Afrand, M. H. Esfe, E. Abedini, and H. Teimouri, "Predicting the effects of magnesium oxide nanoparticles and temperature on the thermal conductivity of water using artificial neural network and experimental data," Physica E: Low-dimensional Systems and Nanostructures, 2016. 
[30] M. Afrand, D. Toghraie, and B. Ruhani, "Effects of temperature and nanoparticles concentration on rheological behavior of Fe3O4-Ag/EG hybrid nanofluid: An experimental study," Experimental Thermal and Fluid Science, vol. 77, pp. 38-44, 10// 2016.

[31] M. A. Amin Asadi, Mohammadhosein Rezaee, Marzieh Siahmargoi, Fahime Asadi, "The effect of temperature and solid concentration on dynamic viscosity of MWCNT-MgO (20-80)/SAE50 hybrid nano-lubricant and proposing a new correlation: An experimental study," International Communications in Heat and Mass Transfer, 2016.

[32] M. Soltanimehr and M. Afrand, "Thermal conductivity enhancement of $\mathrm{COOH}$-functionalized MWCNTs/ethylene glycol-water nanofluid for application in heating and cooling systems," Applied Thermal Engineering, vol. 105, pp. 716-723, 7/25/ 2016.

[33] M. Hemmat Esfe, S. Hadi Rostamian, and A. Alirezaie, "An applicable study on the thermal conductivity of SWCNT-MgO hybrid nanofluid and price-performance analysis for energy management," Applied Thermal Engineering.

[34] R. A. S. o. Heating, A. C. Engineers, and G. Atlanta, ASHRAE handbook: fundamentals: ASHRAE, 2009.

[35] S. Aberoumand and A. Jafarimoghaddam, "Tungsten (III) oxide (WO3) - Silver/transformer oil hybrid nanofluid: Preparation, stability, thermal conductivity and dielectric strength," Alexandria Engineering Journal.

[36] S. Aberoumand, A. Jafarimoghaddam, M. Moravej, H. Aberoumand, and K. Javaherdeh, "Experimental study on the rheological behavior of silver-heat transfer oil nanofluid and suggesting two empirical based correlations for thermal conductivity and viscosity of oil based nanofluids," Applied Thermal Engineering.

[37] I. Mouromtseff, "Water and forced-air cooling of vacuum tubes nonelectronic problems in electronic tubes," Proceedings of the IRE, vol. 30, pp. 190-205, 1942.

[38] R. Prasher, D. Song, J. Wang, and P. Phelan, "Measurements of nanofluid viscosity and its implications for thermal applications," Applied physics letters, vol. 89, p. 133108, 2006.

[39] R. Simons, "calculation corner: comparing heat transfer rates of liquid coolants using the Mouromtseff number," Electronics Cooling, vol. 12, p. 10, 2006.

[40] Y. A. Cengel, "Heat transfer,", in Encyclopedia of Energy Engineering and Technology-3 Volume Set (Print Version), ed: CRC Press, 2007, pp. 822-829.

[41] Y. A. Cengel, Fluid mechanics: Tata McGraw-Hill Education, 2010.

[42] B. Takabi and S. Salehi, "Augmentation of the heat transfer performance of a sinusoidal corrugated enclosure by employing hybrid nanofluid," Advances in Mechanical Engineering, vol. 6, p. $147059,2014$.

[43] R. B. Mansour, N. Galanis, and C. T. Nguyen, "Effect of uncertainties in physical properties on forced convection heat transfer with nanofluids," Applied Thermal Engineering, vol. 27, pp. 240249, 2007.

[44] M. Hemmat Esfe and H. Rostamian, "Non-Newtonian power-law behavior of TiO2/SAE 50 nanolubricant: An experimental report and new correlation," Journal of Molecular Liquids, vol. 232, pp. 219-225, 4// 2017.

[45] M. Hemmat Esfe, M. Afrand, S. Gharehkhani, H. Rostamian, D. Toghraie, and M. Dahari, "An experimental study on viscosity of alumina-engine oil: Effects of temperature and nanoparticles concentration," International Communications in Heat and Mass Transfer, vol. 76, pp. 202-208, 8// 2016.

[46] E.-o.-I. Ettefaghi, H. Ahmadi, A. Rashidi, A. Nouralishahi, and S. S. Mohtasebi, "Preparation and thermal properties of oil-based nanofluid from multi-walled carbon nanotubes and engine oil as nano-lubricant," International Communications in Heat and Mass Transfer, vol. 46, pp. 142-147, 8// 2013. 
[47] E.-o.-I. Ettefaghi, A. Rashidi, H. Ahmadi, S. S. Mohtasebi, and M. Pourkhalil, "Thermal and rheological properties of oil-based nanofluids from different carbon nanostructures," International Communications in Heat and Mass Transfer, vol. 48, pp. 178-182, 11// 2013.

[48] M. Afrand, K. Nazari Najafabadi, and M. Akbari, "Effects of temperature and solid volume fraction on viscosity of SiO2-MWCNTs/SAE40 hybrid nanofluid as a coolant and lubricant in heat engines," Applied Thermal Engineering, vol. 102, pp. 45-54, 6/5/ 2016.

[49] M. Hemmat Esfe, M. Afrand, S. H. Rostamian, and D. Toghraie, "Examination of rheological behavior of MWCNTs/ZnO-SAE40 hybrid nano-lubricants under various temperatures and solid volume fractions," Experimental Thermal and Fluid Science, vol. 80, pp. 384-390, 1// 2017.

[50] J. C. Maxwell, A treatise on electricity and magnetism vol. 1: Clarendon press, 1881.

[51] R. Hamilton and O. Crosser, "Thermal conductivity of heterogeneous two-component systems," Industrial \& Engineering chemistry fundamentals, vol. 1, pp. 187-191, 1962.

[52] D. J. Jeffrey, "Conduction through a random suspension of spheres," in Proceedings of the Royal Society of London A: Mathematical, Physical and Engineering Sciences, 1973, pp. 355-367.

[53] B. C. Pak and Y. I. Cho, "Hydrodynamic and heat transfer study of dispersed fluids with submicron metallic oxide particles," Experimental Heat Transfer an International Journal, vol. 11, pp. 151-170, 1998.

[54] Q. Xue, "Model for thermal conductivity of carbon nanotube-based composites," Physica B: Condensed Matter, vol. 368, pp. 302-307, 2005.

[55] R. M. Turian, D.-J. Sung, and F.-L. Hsu, "Thermal conductivity of granular coals, coal-water mixtures and multi-solid/liquid suspensions," Fuel, vol. 70, pp. 1157-1172, 1991.

[56] B.-X. Wang, L.-P. Zhou, and X.-F. Peng, "A fractal model for predicting the effective thermal conductivity of liquid with suspension of nanoparticles," International Journal of Heat and Mass Transfer, vol. 46, pp. 2665-2672, 7// 2003.

Tables:

Tab. 1 Summary of the recently published literature on thermophysical properties of oil-based nanofluids

\begin{tabular}{|c|c|c|c|c|c|}
\hline Researcher & $\mathrm{I}$ & Base fluid & $\begin{array}{c}\text { Solid } \\
\text { concentration } \\
(\%)\end{array}$ & Temperature & Remarks \\
\hline Hemmat et al. [44] & & Thermal oil & $0.125-1.5 \%$ & 25 to $50^{\circ} \mathrm{C}$ & $\begin{array}{c}\text { Nanofluid behaves as non-Newtonian } \\
\text { fluid }\end{array}$ \\
\hline Asadi et al. [31] & IWCNT & Thermal oil & $0.25-2 \%$ & 25 to $50^{\circ} \mathrm{C}$ & $\begin{array}{l}\text { Newtonian fluid with the maximum } \\
\text { viscosity enhancement of } 65 \%\end{array}$ \\
\hline Hemmat et al & $\mathrm{Al}_{2} \mathrm{O}_{3}$ & Thermal oil & $0.25-2 \%$ & $5-65^{\circ} \mathrm{C}$ & $\begin{array}{l}\text { Newtonian fluid with the maximum } \\
\text { viscosity enhancement of } 132 \%\end{array}$ \\
\hline $\begin{array}{c}\text { Aberoumand and } \\
\text { Jafarimoghadam [20] }\end{array}$ & $\mathrm{Cu}$ & Thermal oil & $0.2-1$ wt $\%$ & $40-100{ }^{\circ} \mathrm{C}$ & $\begin{array}{l}\text { Newtonian fluid with maximum } \\
\text { thermal conductivity and viscosity } \\
\text { enhancement of } 49 \% \text { and } 37 \%\end{array}$ \\
\hline $\begin{array}{c}\text { Aberoumand et al. } \\
{[36]}\end{array}$ & Silver & Thermal oil & $\begin{array}{c}0.12,0.36,0.72 \\
\text { wt } \%\end{array}$ & $40-100{ }^{\circ} \mathrm{C}$ & $\begin{array}{l}\text { Stability, thermal conductivity and } \\
\text { dynamic viscosity measurement }\end{array}$ \\
\hline Asadi et al. [25] & $\mathrm{Mg}(\mathrm{OH})_{2-}^{-}$ & Thermal oil & $0.25-2$ & $25-60^{\circ} \mathrm{C}$ & Thermal conductivity enhancement of \\
\hline
\end{tabular}




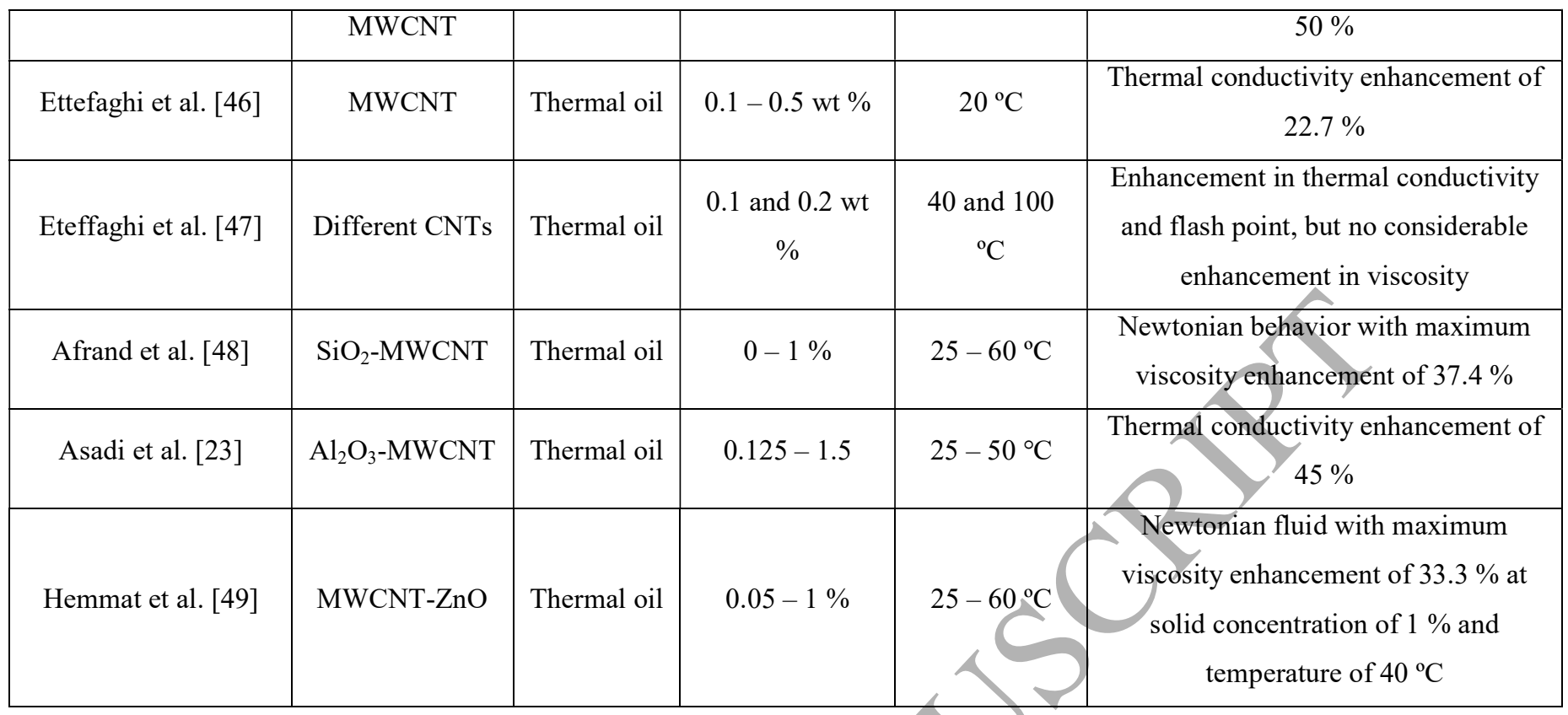

Tab. 2 Characteristics of the utilized nanoparticles

\begin{tabular}{|c|c|c|}
\hline Characteristics & MgO & MWCNT \\
\hline Puri & $99+\%$ & $>97 \%$ \\
\hline & $30 \mathrm{~nm}$ & $\begin{array}{l}\text { Outside diameter: } 20-30 \\
\text { Inside diameter: 5-10 } \\
\text { Length: 10-30 }\end{array}$ \\
\hline Color & White & Black \\
\hline Specific Surface Area $(\mathrm{SSA})\left(\mathrm{m}^{2} / \mathrm{g}\right)$ & $>60$ & 110 \\
\hline Specific Heat Capacity (kJ/kg. k) & 0.937 & 0.71 \\
\hline Density $\left(\mathrm{g} / \mathrm{m}^{3}\right)$ & 3.58 & 2.1 \\
\hline
\end{tabular}

Tab. 3 Detailed information about the Cone and Plate (CAP+2000) viscometer

\begin{tabular}{|c|c|c|c|c|c|}
\hline $\begin{array}{c}\text { Working } \\
\text { Temperature } \\
\text { Range }\end{array}$ & Speeds & Accuracy & Repeatability & Measuring range & Torque range \\
\hline $5-75^{\circ} \mathrm{C}$ & $5-1000 \mathrm{RPM}$ & $\pm 2 \%$ & $\pm 5 \%$ & $0.3-1028 \mathrm{c.P}$ & $\begin{array}{c}797-7,970 \\
\text { dyne.cm }\end{array}$ \\
\hline
\end{tabular}


Tab. 4 Specifications of KD2 Pro thermal analyzer device

\begin{tabular}{|c|c|}
\hline Measurement speed & 2 min \\
\hline Accuracy & $5 \%$ Thermal conductivity/Resistivity \\
\hline Power & 3.0 V CR2-type lithium-ion battery \\
\hline Operating environment & 5 to $40^{\circ} \mathrm{C}$ \\
\hline Range of measurement & 0.1 to $2 \mathrm{~W} / \mathrm{m} .{ }^{\circ} \mathrm{C}$ \\
\hline Sensor & Needle length: $60 \mathrm{~mm}$ \\
& Needle diameter: $0.9 \mathrm{~mm}$ \\
Cable length: $72 \mathrm{~cm}$
\end{tabular}

Tab. 5 Summary of the frequently used models to predict the thermal conductivity

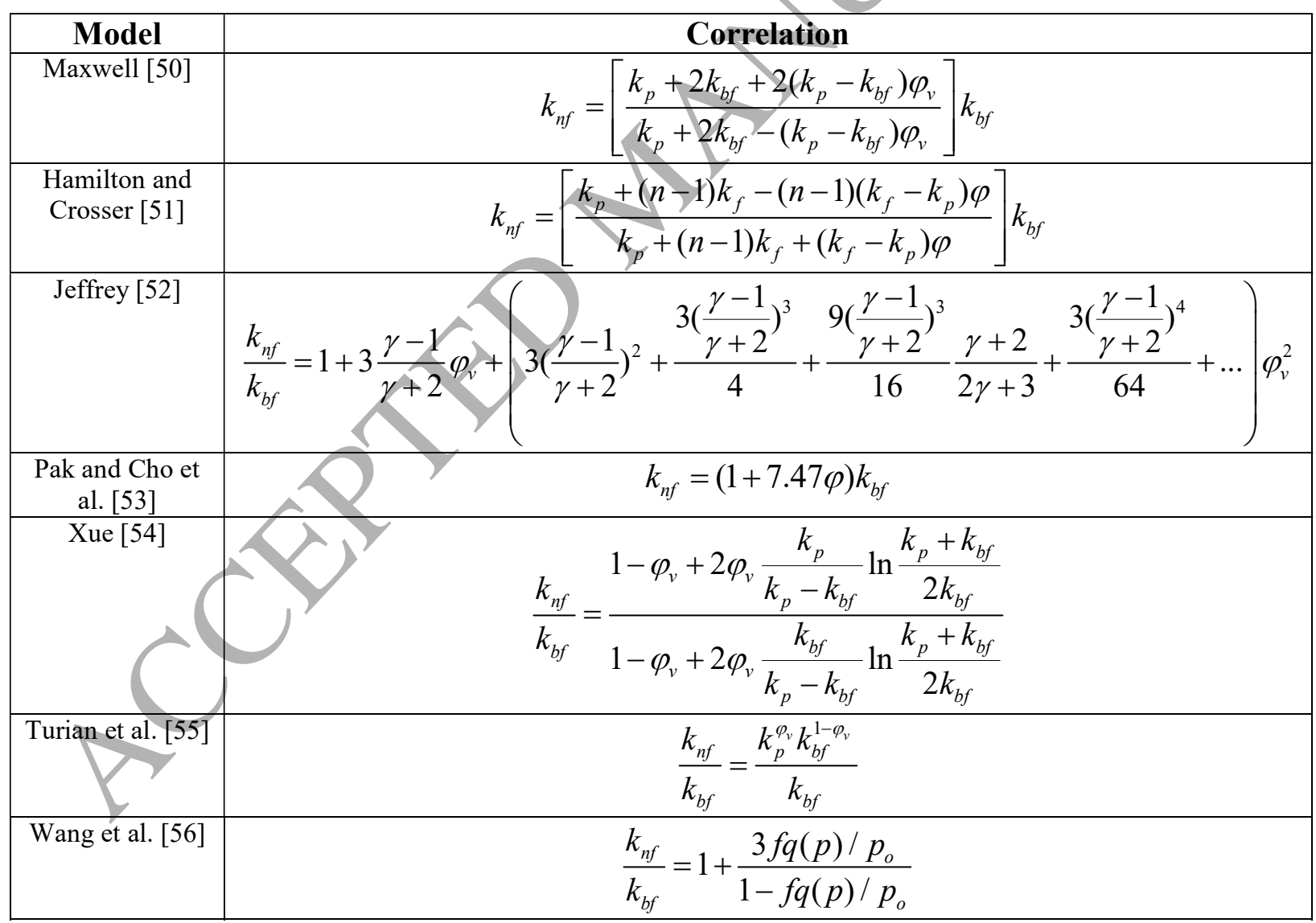


Figures:

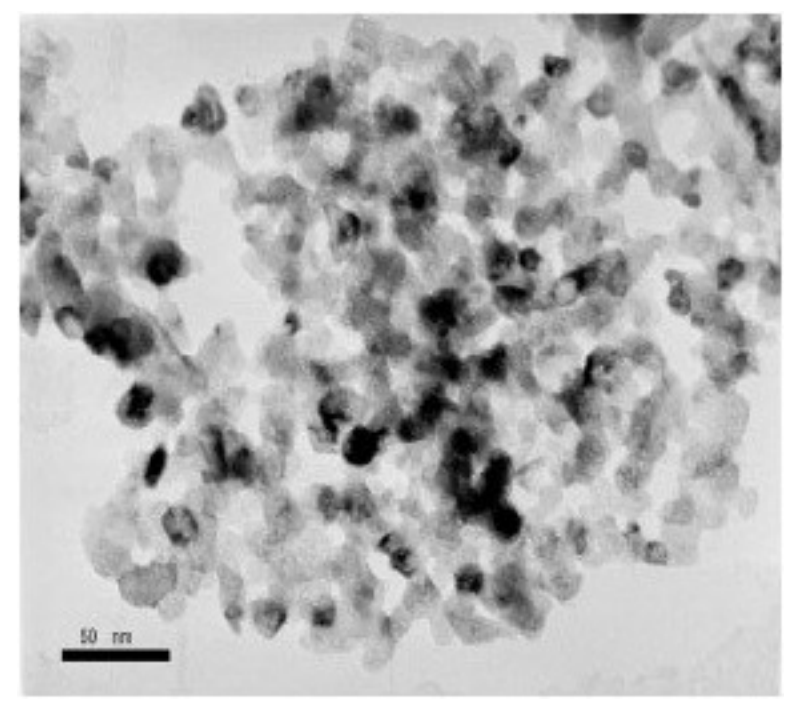

A

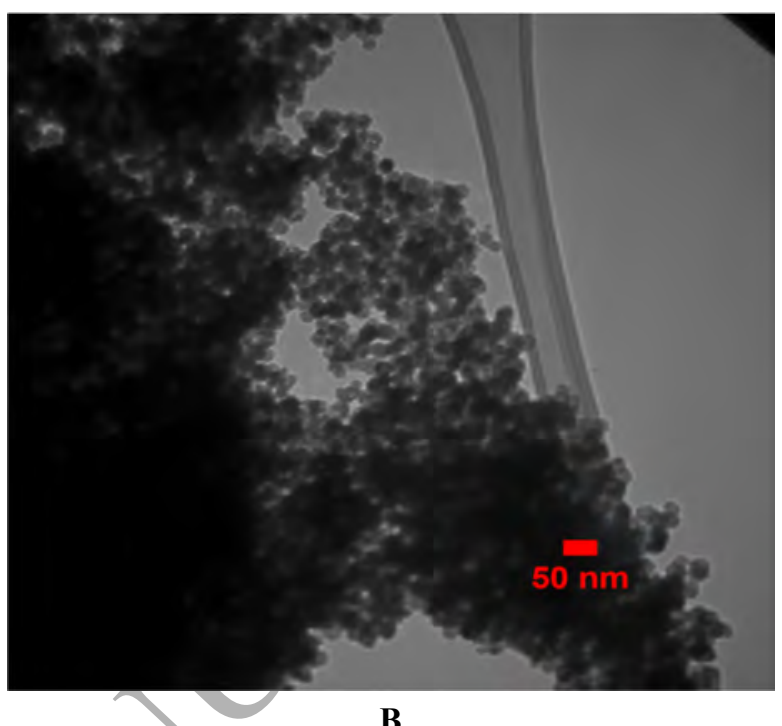

B

Fig.1 TEM image of A) MgO, and B) MWCNT nanoparticles [31]
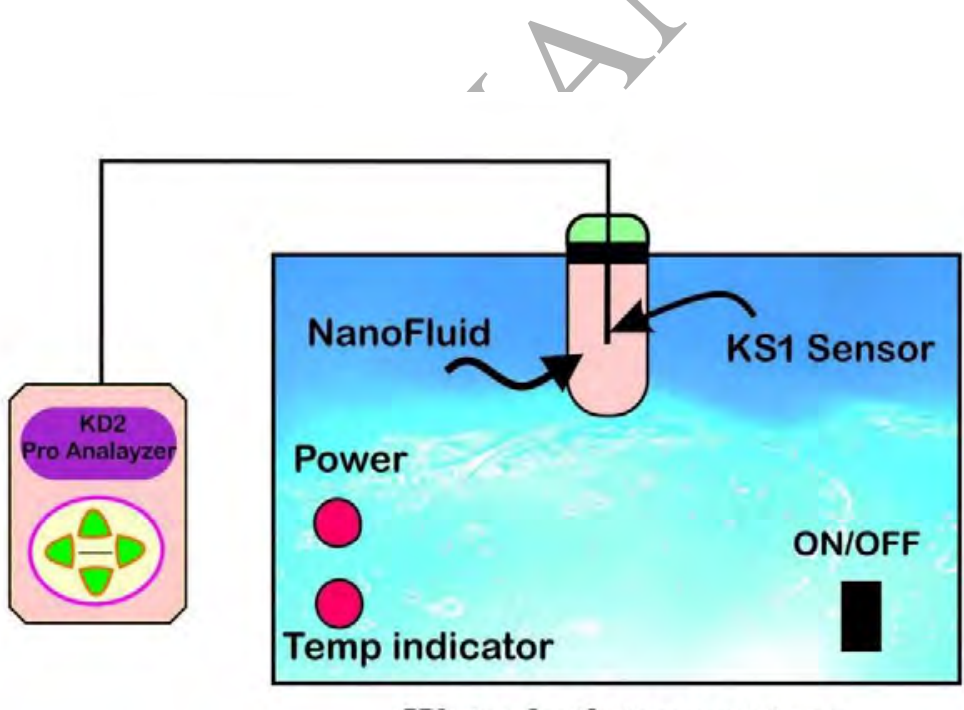

Water bath temperature

Fig. 2 schematic view of thermal conductivity set up 


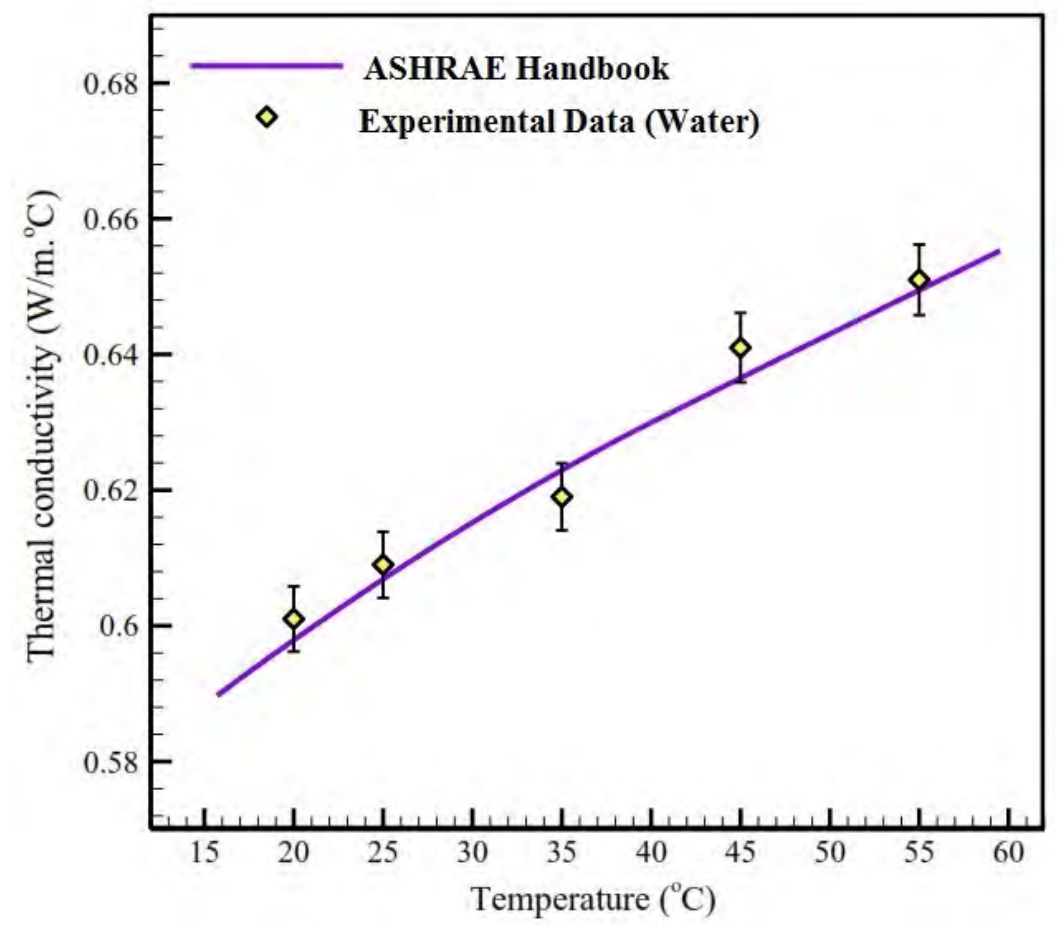

Fig. 3 Comparison between the measured thermal conductivity of water with the data available in ASHRAE handbook [34]

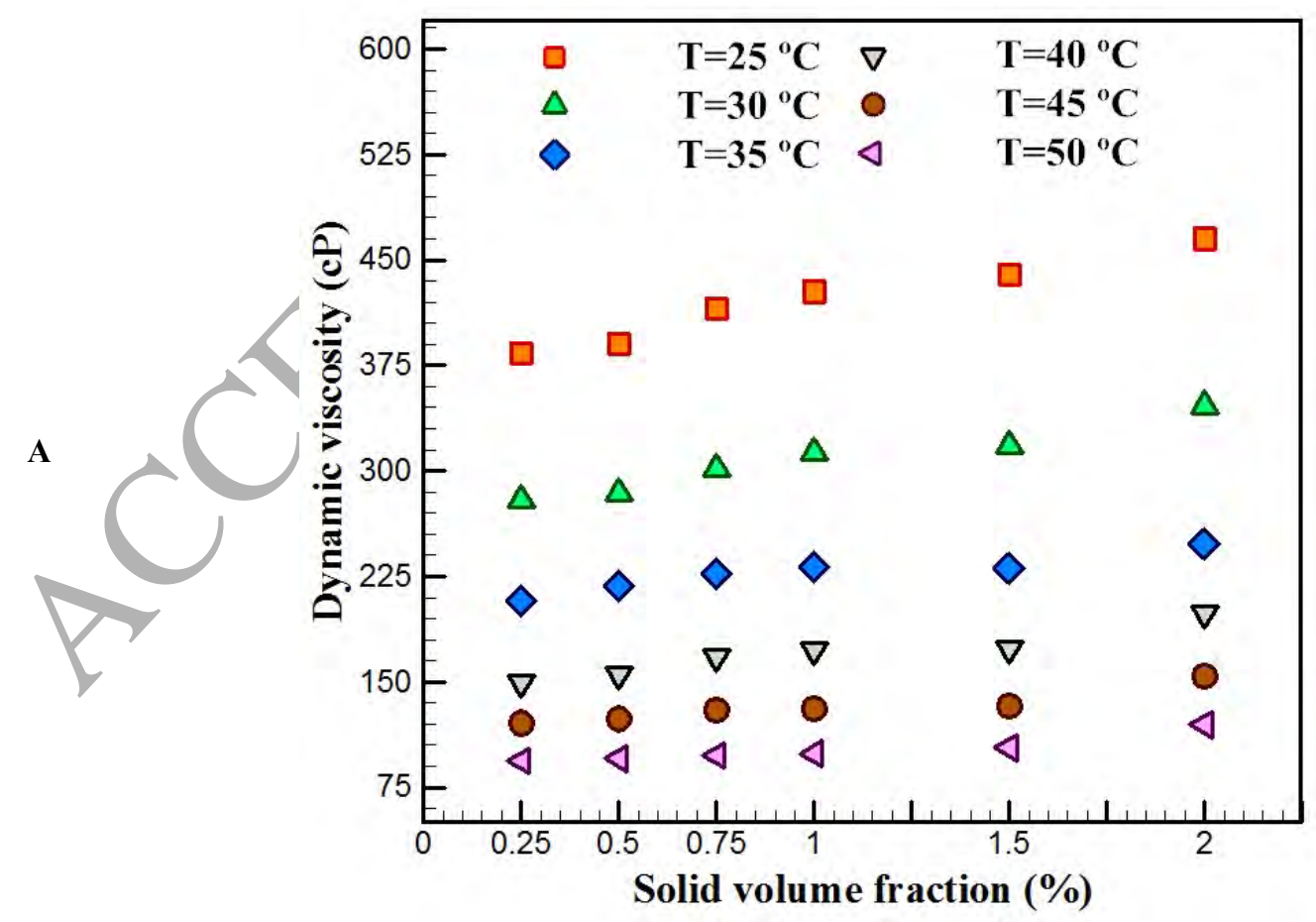




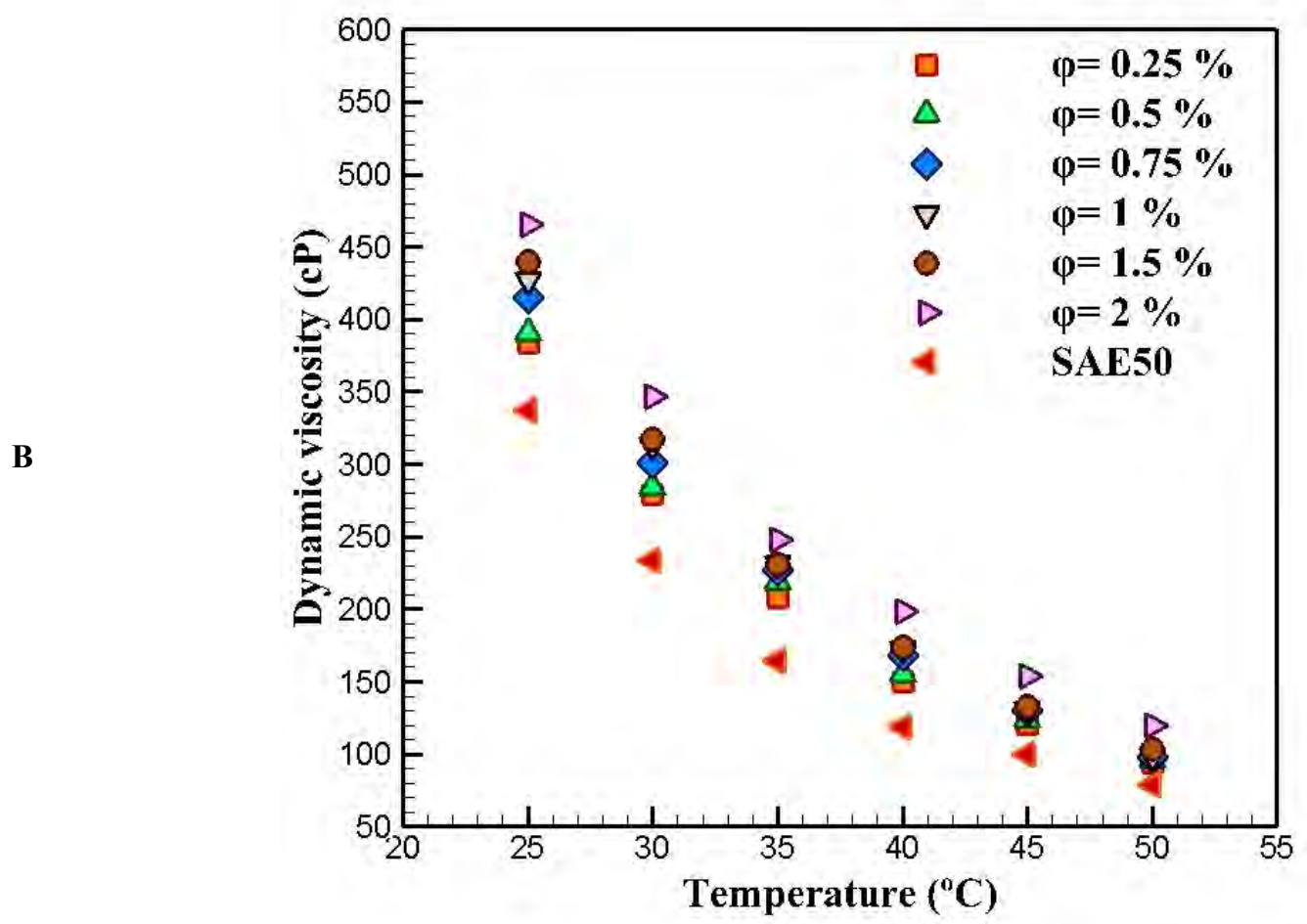

Fig. 4 Dynamic viscosity concerning A) solid concentrations in different temperatures, and B) temperature in different solid concentrations [31]

A

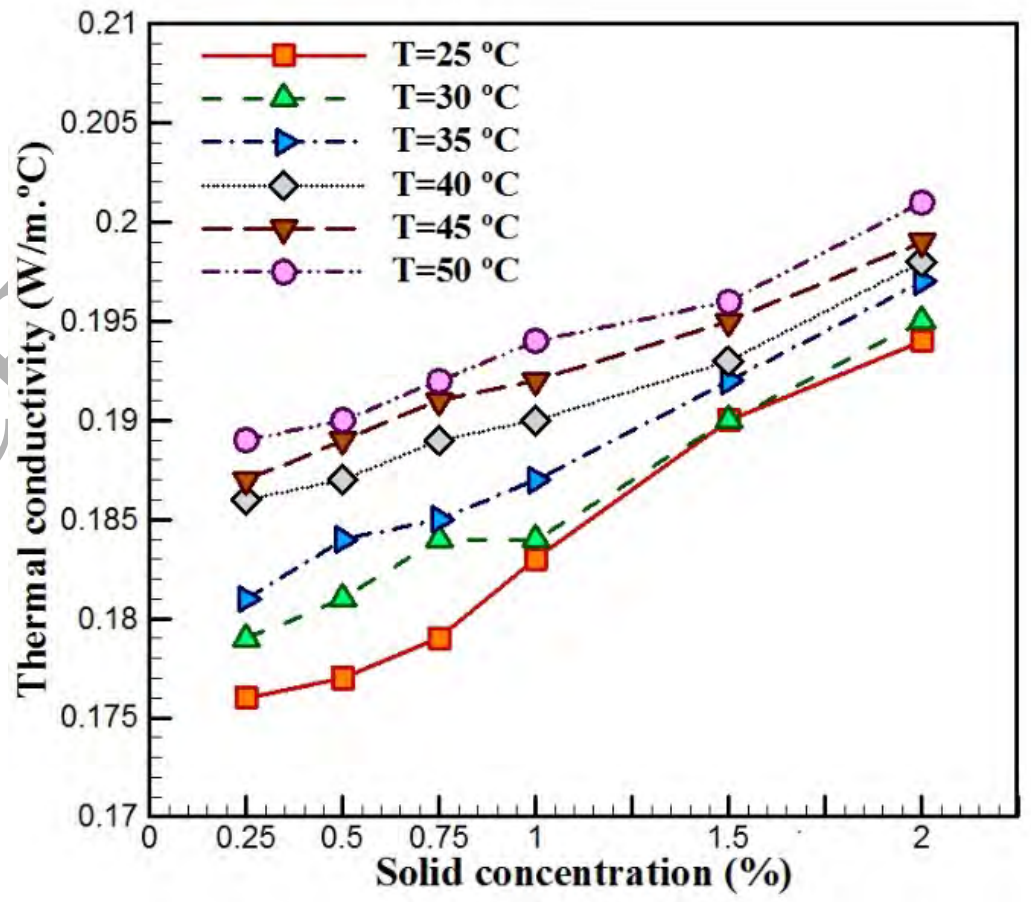


B

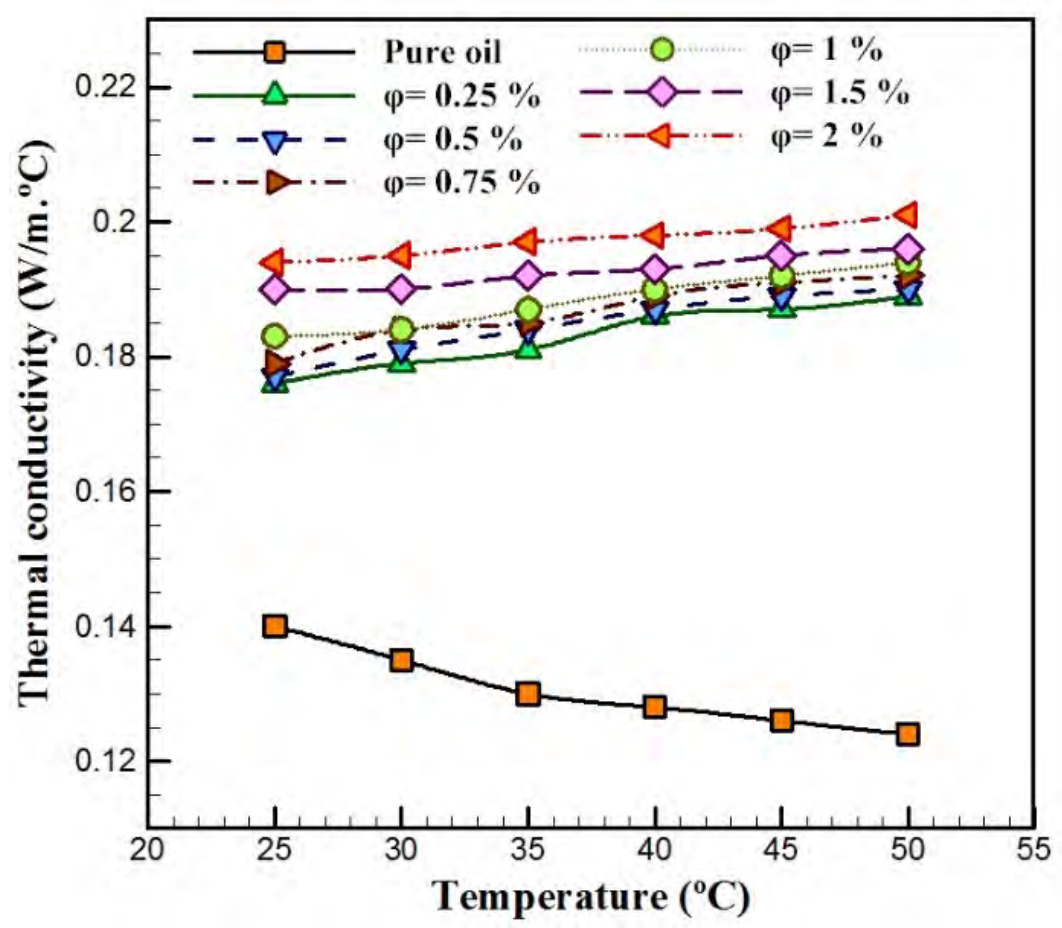

Fig. 5 Thermal conductivity concerning A)solid concentration in different temperatures, and B) temperature in different solid concentrations

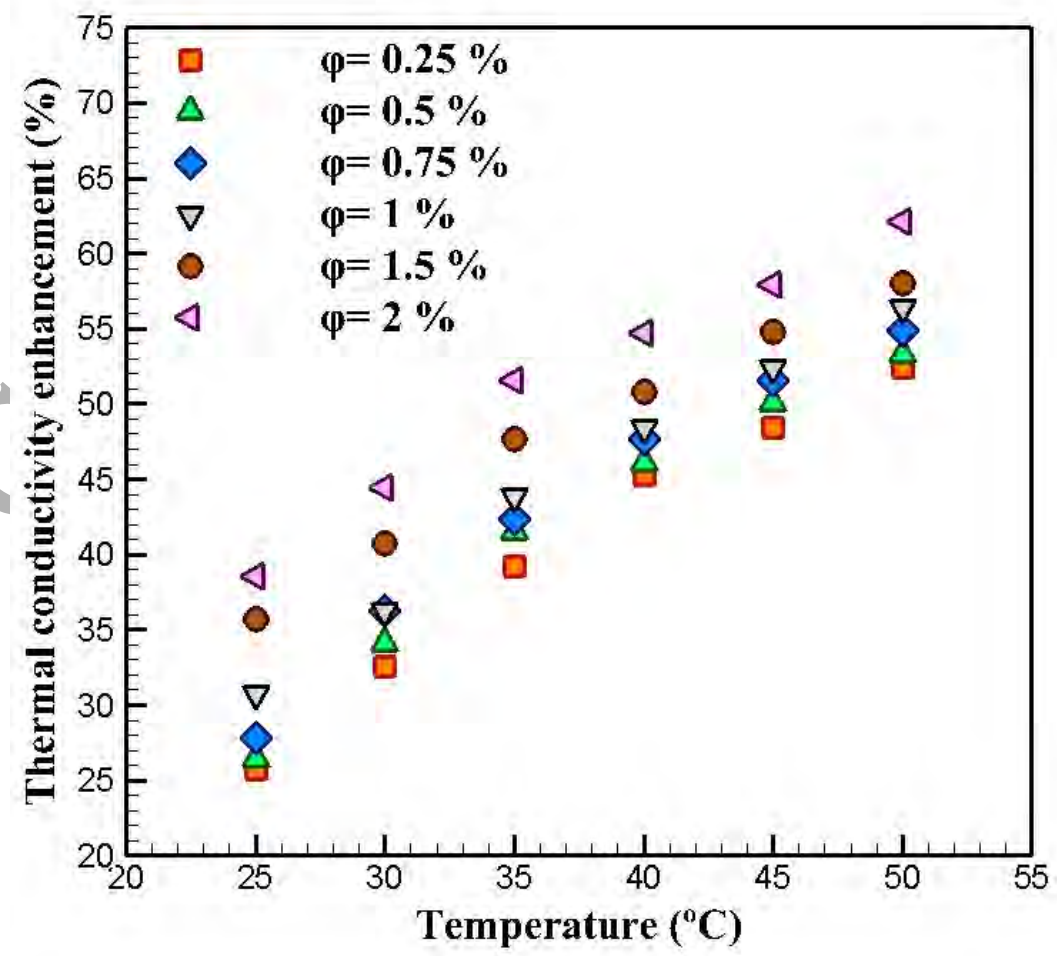


Fig. 6 Thermal conductivity enhancement
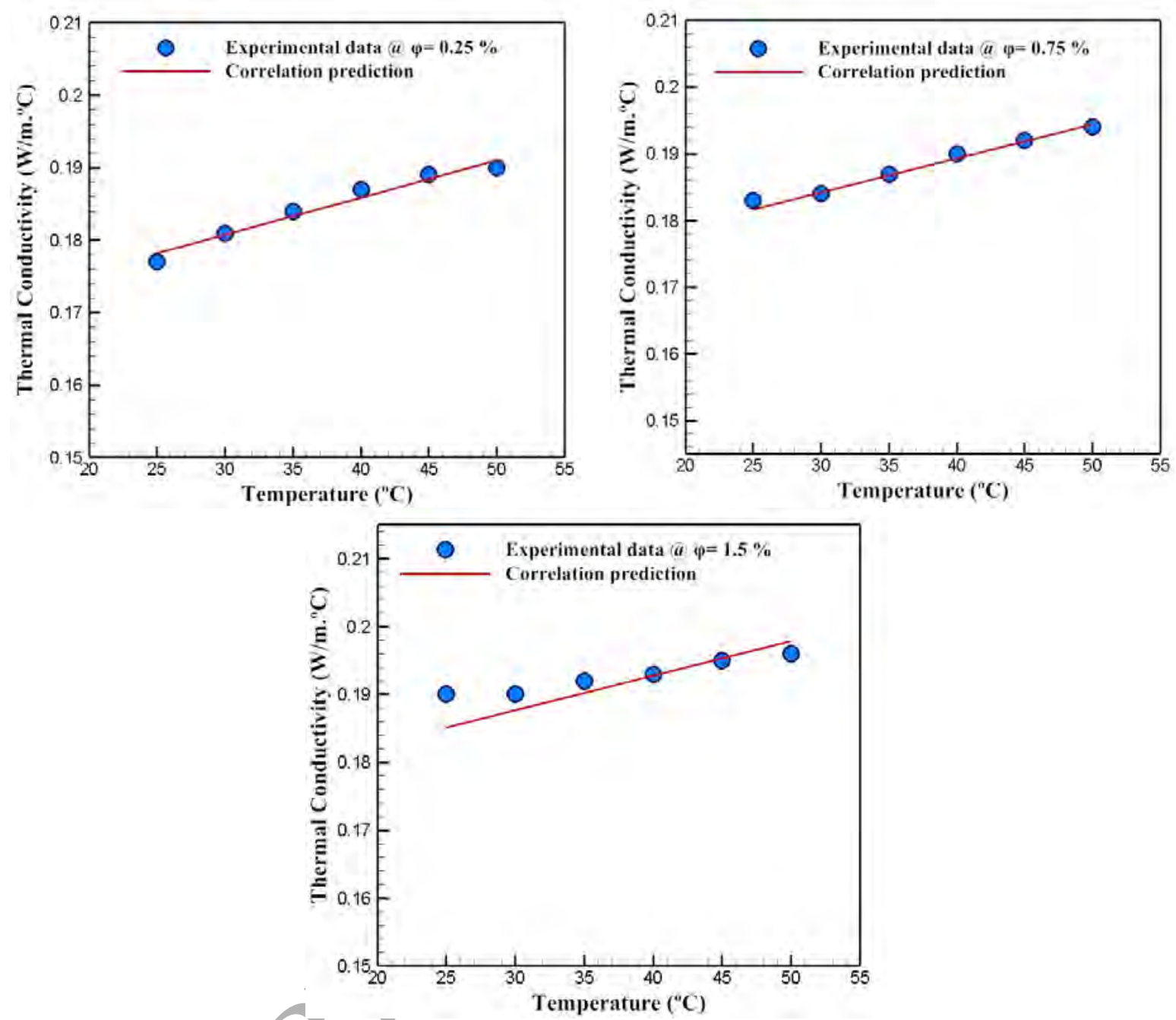

Fig. 7 Comparison between the experimental data and correlation output for thermal conductivity 


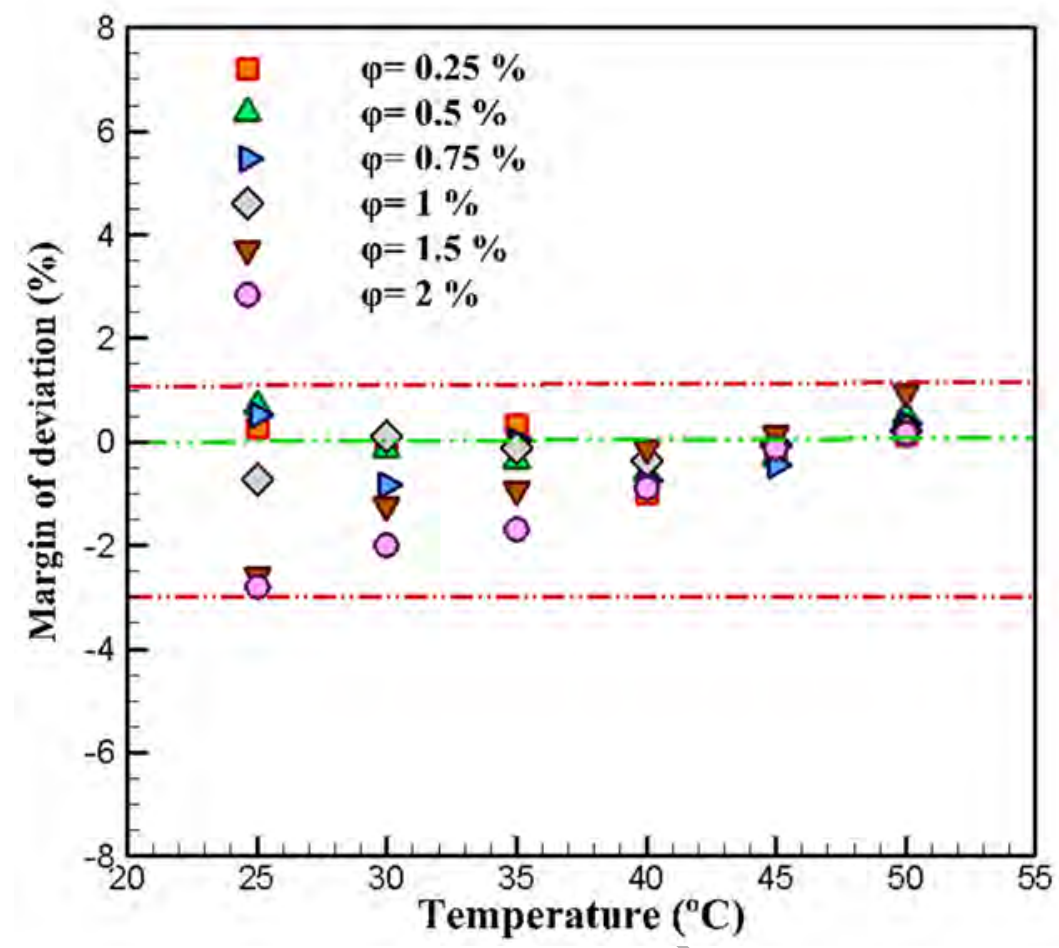

Fig. 8 Deviation analysis of the proposed model to predict the thermal conductivity

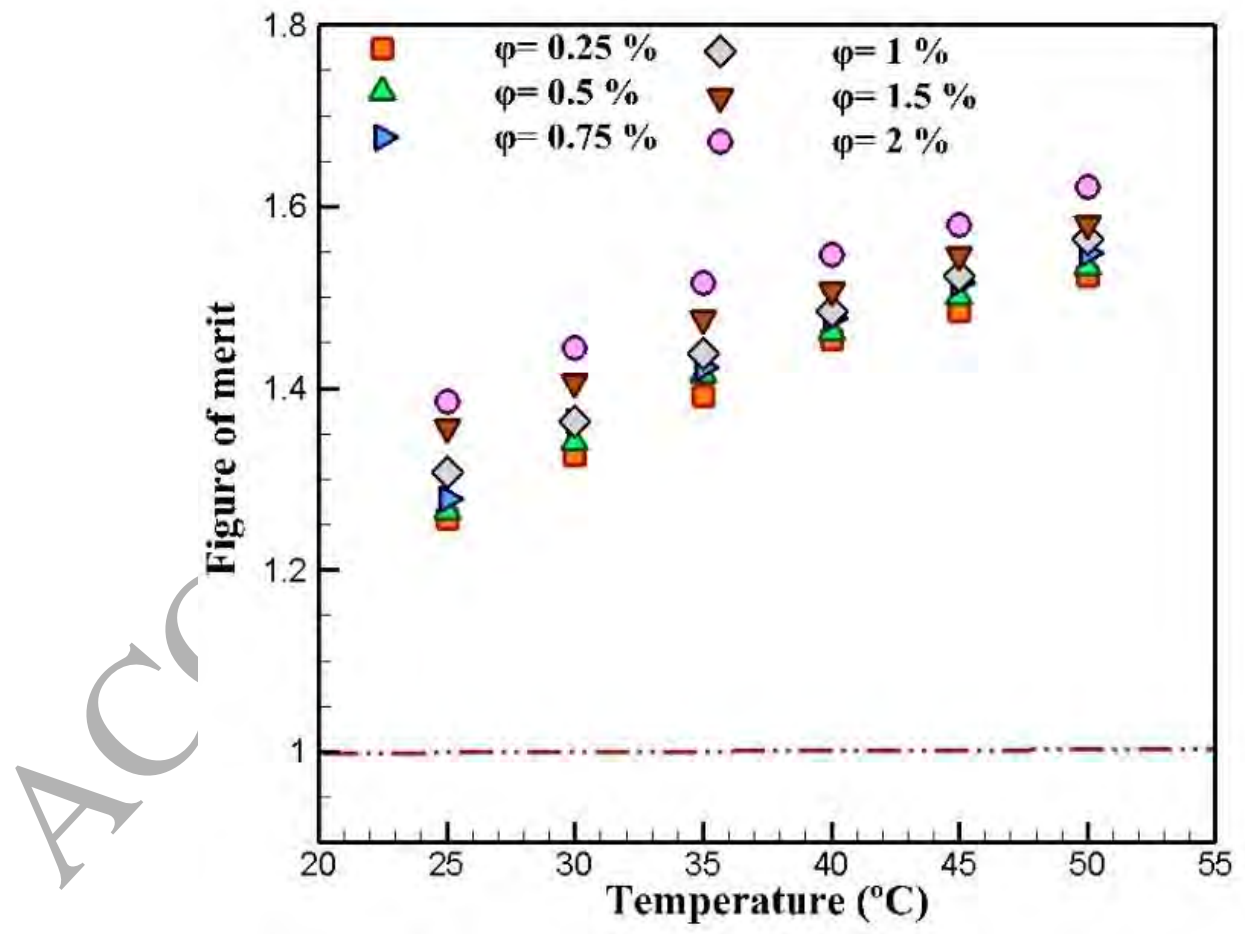

Fig. 9 Heat transfer efficiency for internal laminar flow regime based on Mouromtseff number 


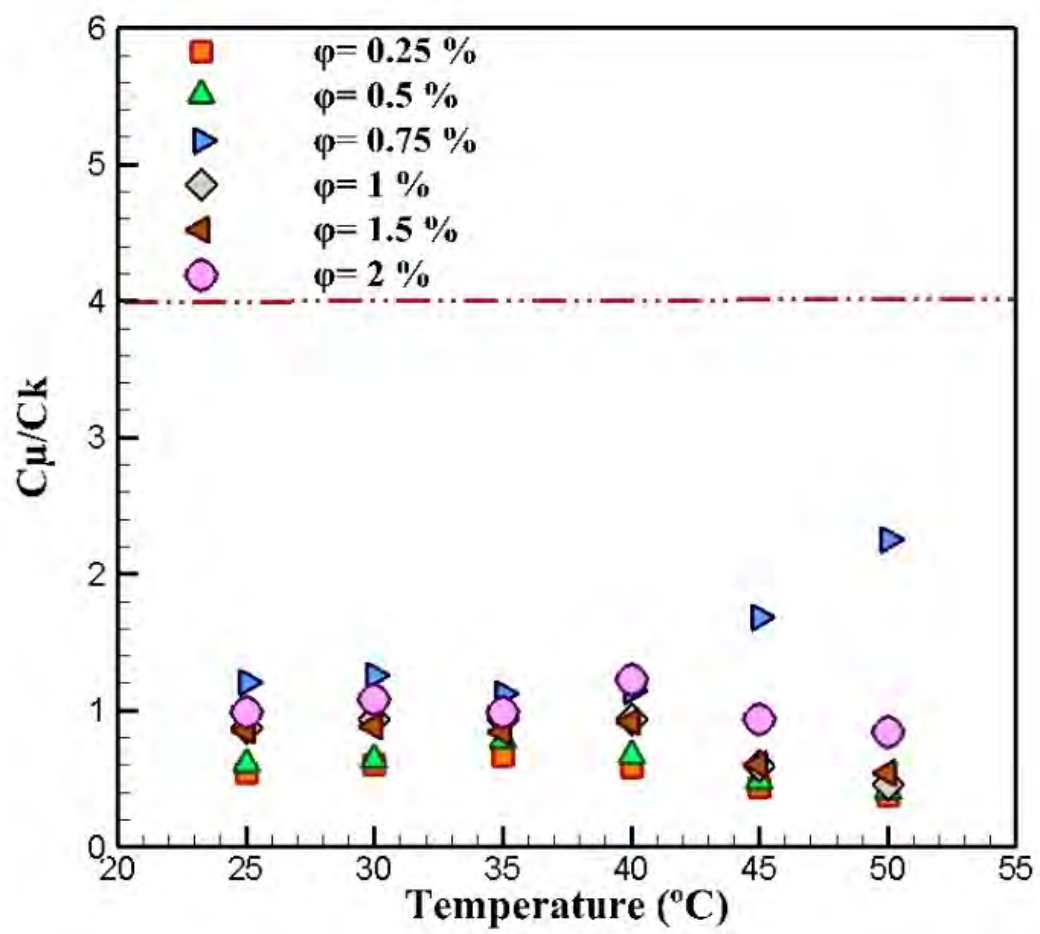

Fig. 10 Heat transfer performance for internal laminar flow regime based on Prasher et al.

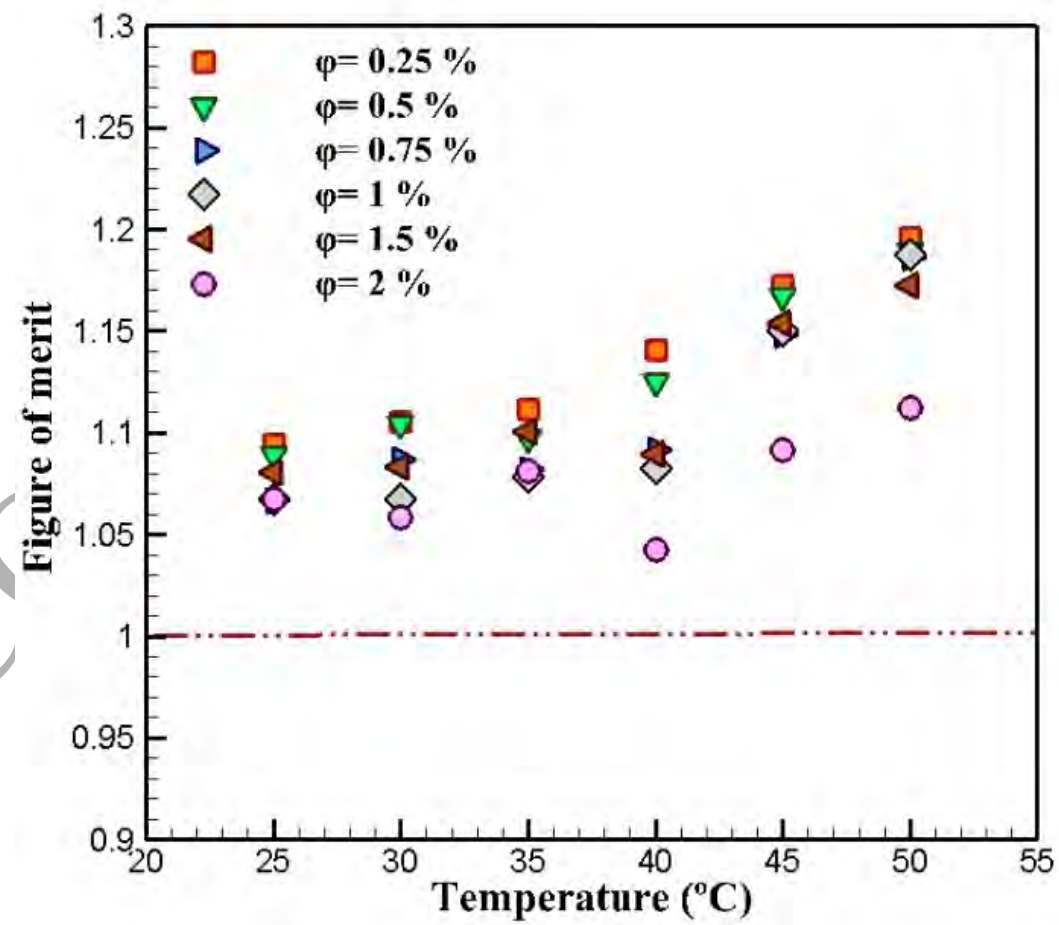

Fig. 11 Heat transfer efficiency for internal turbulent flow regime based on Mouromtseff number 
A

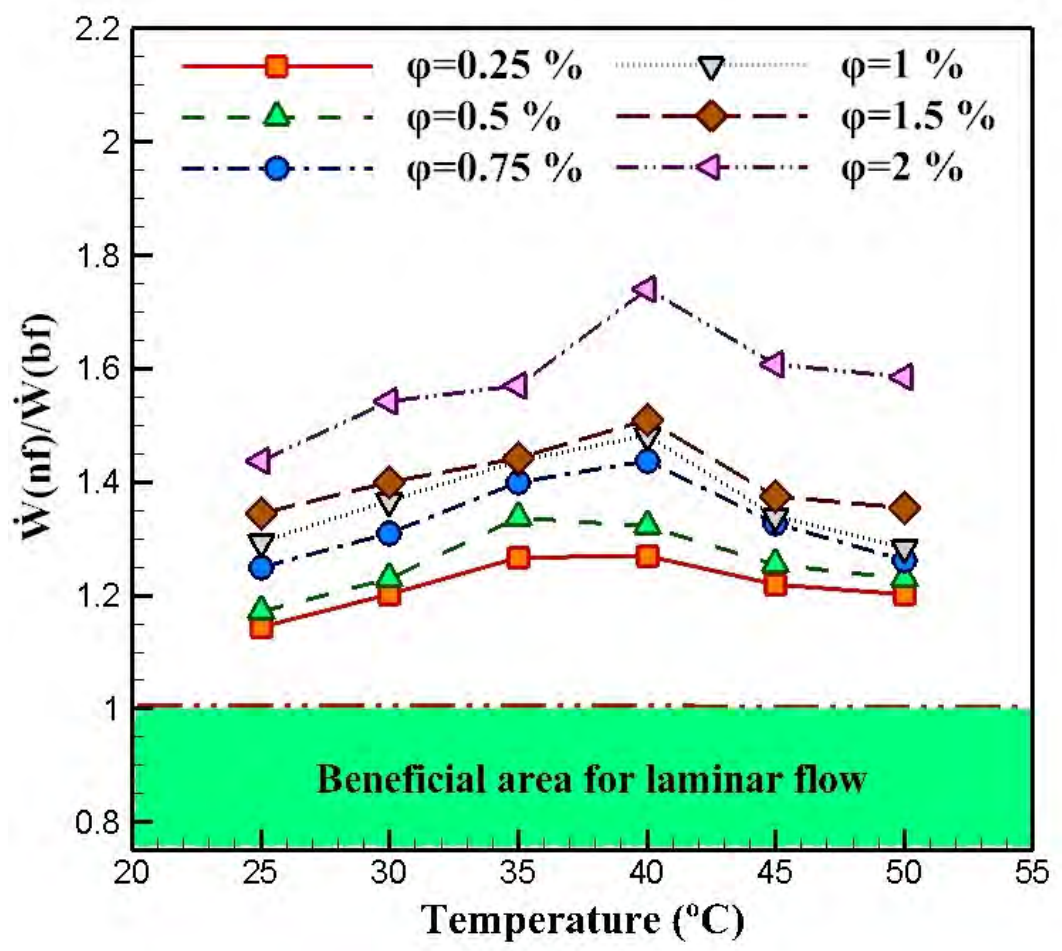

B

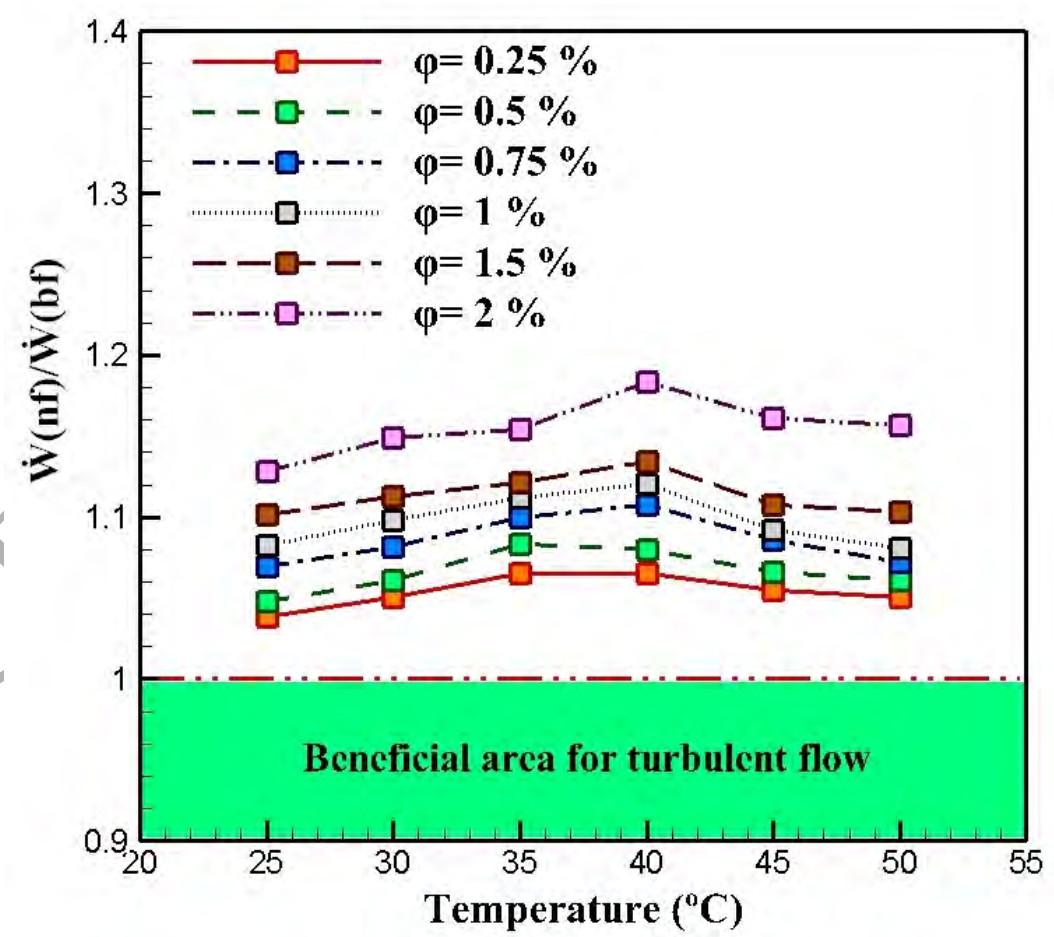

Fig. 12 Variation of pumping power in both the internal laminar and turbulent flow regimes in different solid concentrations and temperatures 